\section{Analysis of Factors Associated with Orthodontic Microscrew Failure}

Adriano Dobranszki ${ }^{1,2}$, Jorge Faber ${ }^{3}$, Isabela Von Muehlen Carvalho Scatolino ${ }^{4}$, Nara Pereira d'Abreu Cordeiro Dobranszki², Orlando Ayrton de Toledo ${ }^{3}$

The objective of this study was to examine whether factors such as insertion site, patient's facial pattern, microscrew features, type of tooth movement desired, level of experience handling orthodontic microscrews and operator expertise were associated with failure of microscrews. After the approval of an ethics committee, 166 patients of one practice signed an informed consent and received 293 microscrews randomly distributed by 3 operators with different levels of practical experience and expertise in handling microscrews. The microscrews were observed in a period of 365 days or as long as orthodontic forces had to be applied and independent variables were recorded. Analysis by the chi-square test did not produce enough evidence as to allow the assertion that there was an association between the variable "failure" and the variables "maxilla" $(p=0.4775)$, "face" ( $p=0.1081)$, "facial pattern" ( $p=0.7522)$, "microscrew length" $(p=0.9113)$, "desired movement" ( $p=0.0584)$, and "operator" ( $p=0.5785)$. The variable "insertion side" was significantly associated with "failure" ( $p=0.0022)$. In a 365 -day survival analysis, the Log Rank test yielded a p-value of 0.00178 for the curve of variable "insertion side," and showed no significant differences for other variables. With a total success rate of $87.38 \%$, the only variable found to be significant was "insertion side" ( $p=0.0022)$, with 3.088 more likelihood of a microscrew failing if placed on the left side than on the right side. The procedure of inserting microscrews involved a rapid learning curve for an inexperienced operator, which justifies their placement by orthodontists.
'UnB - University of Brasília and, Brasília, DF, Brazil

${ }^{2}$ FACIPLAC - Faculdades Integradas do Planalto Central, Brasília, DF, Brazil

${ }^{3}$ UnB - University of Brasília,

Brasília, DF, Brazil

${ }^{4}$ Private Practice, Brasília, DF, Brazil

Correspondence: Prof. Dr. Adriano Dobranszki, SRTVS, 701, Bloco A, sala 308, 70.340-907 Brasília, DF, Brasil. Tel: : 5561 3321-7010. e-mail: dobranszki@uol.com.br

Key Words: mini-implants, microscrews, success rate, survival analysis.

\section{Introduction}

Orthodontic microscrews (OMSs) are widely used in contemporary orthodontics. However, they exhibit a relatively high failure rate. After placement, approximately $13.5 \%$ (1) of OMSs lose stability and no longer serve as anchorage for tooth movement, which translates into clinical failure. This failure is greater than that of dental implants (2) and possibly discourages some clinicians from utilizing this important resource.

OMS failure may be multifactorial and the factors most frequently studied are classified into categories of related factors (1): 1) the patient, 2) the clinician, 3) the form and site of insertion, 4) the treatment, 5) complicating factors, and 6) the microscrew. Amongst these categories, some variables deserve special attention from the orthodontists because they are related to the necessary knowledge for the orthodontic diagnosis (facial pattern) $(3,4)$, orthodontic mechanics (upper/lower jaw $(5,6)$, insertion side $(5,7)$, type of desired movement $(4,8,9)$, and for the installation of the microscrew (caliber of the microscrew), teacher/student (10), learning curve $(9,11,12)$.

Some studies have been performed in humans with the aim of studying the factors associated with the successful clinical use of OMSs, and some orthodontists still believe that the OMSs must be inserted by implant dentists or surgeons because the procedure would require specialized skills beyond their knowledge domain. Several factors have been associated with OMS failure, including operator experience, but not operators from different specialties. The mini-implant advent created a new implantation site (interadicular septum) that was not usual for surgeons, implantodontists and orthodontists. As consequence, scientific literature has highlighted that mini-implant insertion requires specialized skills regardless of professional specialty. Therefore, both, orthodontists and surgeons, have to undergo a learning curve to achieve clinical excellence in installing mini-implants (6).

The aim of this study was to determine whether or not certain factors, such as insertion site, patient's facial pattern, microscrew characteristics, type of tooth movement desired, level of experience in handling microscrews and operator specialty, are associated with the failure of microscrews.

\section{Material and Methods}

This study was approved by the Research Ethics Committee of the Medical School of the University of Brasilia (CEP-FM 007/2012 UnB). All the patients signed an informed consent before surgery. This prospective case series study involved the placement of 293 orthodontic microscrews (OMSs) in 166 consecutive patients (62 male and 104 female) with a mean age of 25.8 years (SD 10.4 years), treated in just one private orthodontics practice 
in Brasilia, Brazil. The placement site was defined by the orthodontist before the patients were distributed, according to a table of random numbers, among three dental surgeons with different levels of practical experience and expertise in handling microscrews.

The patients were subjected to orthodontic treatment and received at least one self-drilling OMS (High Utility Line; Sistema de Implante SIN, São Paulo, SP, Brazil) in the posterior buccal regions of the maxilla or mandible (1.6 $\mathrm{mm}$ diameter, $1 \mathrm{~mm}$ collar size, 6 or $8 \mathrm{~mm}$ long) with a manual screwdriver, and anterior $(1.6 \mathrm{~mm}$ diameter, $1 \mathrm{~mm}$ collar size 6 or $8 \mathrm{~mm}$ long) or posterior (1.8 mm diameter, $3 \mathrm{~mm}$ collar size - to compensate for the thickness of the palatal mucosa -8 or $10 \mathrm{~mm}$ long) region of the palatal slope (none was placed in the mid-palatal area), with an electric handpiece, after submucosal anesthesia. The OMSs were placed in the buccally in the attached gingiva adjacent to the mucogingival junction at an angle of $60^{\circ}$ to $90^{\circ}$ relative to the long axis of the teeth in the maxilla and mandible, or perpendicular to the alveolar ridge on the palatal surface. The choice for a specific length was based on a clinical estimation by the operator before installation and the orthodontist completed the orthodontic treatment.

An orthodontic force of less than $200 \mathrm{~g}(\mathrm{cN})(4,8,13-$ 15) was applied immediately after placement of each OMS $(5,8,11,13,14)$ by means of elastomeric chains $(3,8,11,15)$. Analgesics were prescribed for the day of OMS placement. To be considered successful there had to be enough stability to activate, without pain, the OMS for as long as orthodontic forces had to be applied (16) (in this study, at least 365 days) and independent variables were recorded (Table 1).

\section{Statistical Analysis}

An association between failure rate and the variables comprised in Table 2 was investigated by means of chi- square tests with a $5 \%$ significance level. The significant variables were processed through a logistic regression model that sought to explain the failure rate by means of the independent variables shown in Table 2.

Where differences between specific operators were analyzed, logistic regression was used in order to create a model capable of describing the failure rate by means of the operator and each of the independent variables shown in Table 2. For each independent variable, a bivariate analysis was performed and then the appropriate statistical test was performed to evaluate any effects that may have been induced by an interaction between the operator and each of the factors, i.e., whether or not the failure rate caused by the action of placing the microscrew was different depending on the operator.

A survival time was defined as the time observed from placement of the microscrew up until it fell out. The loss of a microscrew was censored after 365 days of observation, as well as when no failure occurred and it had been observed for a period shorter than 365 days (cases where the patient moved out of town, gave up treatment or deceased). Survival probability estimates were carried out for each operator using Kaplan Meier's nonparametric estimator, and survival curves were compared to analyze the difference between survival probabilities in the implants of each operator. Thereafter, the Log Rank or Wilcoxon test was employed, whenever applicable, to check whether the probabilities were statistically different when testing hypotheses HO (distributions of the survival curves are identical) and $\mathrm{H} 1$ (distributions of the survival curves are different).

\section{Results}

A total of 177 patients were recruited but 11 patients declined ( 6 moved to another city, 4 quitted the treatment

Table 1. Description of the independent variables and their measurement methods

\begin{tabular}{|c|c|}
\hline Variable & Measurement Method \\
\hline Maxilla & 1. Upper or 2. Lower \\
\hline Side & 1. Right or 2. Left \\
\hline Face & 1. Palatal or 2. Buccal \\
\hline Facial Pattern* & 1. Brachyfacial $\left(\mathrm{FMA}<21^{\circ}\right) ; 2$. Dolichofacial $\left(\mathrm{FMA}>29^{\circ}\right)$; or 3. Mesofacial (FMA between $21^{\circ}$ and $29^{\circ}$ ) \\
\hline Length & 1. $[6 \mathrm{~mm}] ; 2 .[8 \mathrm{~mm}] ;$ or $3 .[10 \mathrm{~mm}]$ \\
\hline Movement & Desired movement: 1. Molar distalization; 2. Intrusion; 3. Protraction; or 4. Retraction \\
\hline Operator & $\begin{array}{l}\text { Each of the operators involved had different levels of experience: } \\
\text { 1. Professor of orthodontics with a master's degree and no experience placing miniscrews. } \\
\text { 2. Professor specialized in implant dentistry and experienced in the area, having placed approximately } 50 \text { miniscrews. } \\
\text { 3. Professor with a Ph.D. and extensive experience in implant dentistry, having placed more than } 200 \text { miniscrews. }\end{array}$ \\
\hline
\end{tabular}

*These angles represent subjects within a standard deviation of 1, according to Tweed's normative values (Baumgaertel 2010). 
before conclusion and 1 deceased during the treatment) and were excluded from the sample. Analysis of this sample by the chi-square test showed no association between the variable "failure" and the variables "operator" $(p=0.5785)$, "maxilla" ( $p=0.4775)$, "face" $(p=0.1081)$, "facial pattern" ( $p=0.7522)$, "microscrew length" $(p=0.9113)$ and "desired movement" ( $p=0.0584$ ) (Table 2). Since there was no significant difference among the operators, the data from the three clinicians were pooled for the subsequent analyses. The only variable found to have a significant association with "failure" was "insertion side" $(p=0.0022)$,

Table 2. Failure rate, success rate/total number of minicrews inserted, and significance in accordance with the clinical variables

\begin{tabular}{|c|c|c|c|c|}
\hline Variable & Failure & Success & $\mathrm{p}$ & $\begin{array}{l}\text { Total } \\
\text { (n) }\end{array}$ \\
\hline \multicolumn{5}{|l|}{ Operator } \\
\hline Orto, M.S. & $15(15.15)$ & $84(84.85)$ & \multirow[t]{3}{*}{0.5785} & 99 \\
\hline Implant, Esp. & $12(12.50)$ & $84(87.50)$ & & 96 \\
\hline Implant, Ph.D. & $10(10.20)$ & $88(89.80)$ & & 98 \\
\hline Maxilla & $n(\%)$ & $n(\%)$ & & \\
\hline Upper & $34(13.12)$ & 225 (86.88) & \multirow{2}{*}{0.4775} & 259 \\
\hline Lower & $3(8.82)$ & $31(91.18)$ & & 34 \\
\hline \multicolumn{5}{|l|}{ Side } \\
\hline Right & $11(7.58)$ & 145 (92.94) & \multirow[t]{2}{*}{$0.0022^{* * *}$} & 156 \\
\hline Left & $26(18.97)$ & $111(81.03)$ & & 137 \\
\hline \multicolumn{5}{|l|}{ Face } \\
\hline Palatal & $25(15.43)$ & $137(84.57)$ & \multirow{2}{*}{0.1081} & 162 \\
\hline Buccal & $12(9.16)$ & $119(90.84)$ & & 131 \\
\hline \multicolumn{5}{|l|}{ Facial Pattern } \\
\hline Brachyfacial & 11 (12.79) & $75(87.21)$ & \multirow{2}{*}{0.7522} & 86 \\
\hline Dolichofacial & $16(14.54)$ & $94(85.45)$ & & 110 \\
\hline Mesofacial & $10(10.30)$ & 87 (89.70) & & 97 \\
\hline \multicolumn{5}{|l|}{ length } \\
\hline $6 \mathrm{~mm}$ & $7(15.90)$ & $37(84.10)$ & \multirow[t]{3}{*}{0.9113} & 44 \\
\hline $8 \mathrm{~mm}$ & 20 (11.69) & $151(88.31)$ & & 171 \\
\hline $10 \mathrm{~mm}$ & $10(12.50)$ & $68(87.50)$ & & 78 \\
\hline \multicolumn{5}{|l|}{ Movement } \\
\hline Molar distalization & 23 (17.97) & $105(80.03)$ & \multirow[t]{4}{*}{0.0584} & 128 \\
\hline Intrusion & $5(6.75)$ & $69(93.24)$ & & 74 \\
\hline Protraction & $4(8.70)$ & 42 (91.30) & & 46 \\
\hline Retraction & $5(11.11)$ & $40(88.89)$ & & 45 \\
\hline
\end{tabular}

*** $p<.05$.

348 with a significantly higher failure rate on the left side $(18.97 \%)$ than on the right side $(7.58 \%)$.

Given that the association was considered significant in terms of the factor "insertion side," the predictive model values associated with the variable "failure" indicated that an OMS placed on the right is 3.088 times more likely not to fail than an OMS inserted on the left side.

No relationship between failure and dental arch, face, facial pattern and microscrew length could be considered significant, except for the factor "insertion side" (estimate = 0.6093 , standard error $=0.2055$, Wald chi-square $=8.7924$, and $p=0.0030$ ), explained by the same model shown in Table 2. The interaction between the "side" and all operators was not considered significant, the amount of OMS placed on the left side and failure rate for each operator was 44 and 15.38\% (operator 1), 34 and 20.93\% (operator 2), 37 and 15.91\% (operator 3) (Fig. 1).

The total percentage of failures was similar for the three operators, and was considered not significant ( $p=0.5785)$, although the average number of days before the first operator experienced microscrew failure (73.87) was lower than the average number of days experienced by the second operator (151.42), which was also lower than the average days of the third operator (218.70) (Table 3).

A 365-day survival analysis revealed differences in the charts between survival odds over time. The Log Rank test was applied to check for differences between the curves, yielding as a result a p-value of 0.505 for operator (Fig. 2), 0.928 for length, 0.632 for dental arch, and 0.132 for face. Therefore, there is no evidence that curves are indeed different based on the values observed in the sample. Test results showed a p-value of 0.00178 for the curve of variable "insertion side," underscoring a difference between the survival curves of implants placed on the right side vs. the left side (Fig. 3).

\section{Discussion}

In the present study, the overall success rate was $87.38 \%$, with 37 losses out of 293 microscrews inserted in 166 patients. Recent studies show success rates for single minicrews ranging from $57 \%$ (17) to $93.43 \%$ (7). Failure is defined as loss of primary (18-21) or secondary (19) stability during treatment. A low failure rate leads to limitations in statistical analyses, which generally have low statistical power. This may cause variations in the results obtained in published studies.

The present study corroborates other investigations $(3,4,7,12)$ which found no statistically significant differences in failure rates between OMSs placed in the upper vs. lower jaw ( $p=0.4775)$, or in the palatal mucosa $(5,7,8,13)$ compared to other sites $(p=0.1081)$. In agreement with other studies $(2,4,5,8,12,13,17,20)$, the results of this 
study showed that OMS length has no bearing on rate of failure ( $p=0.9113$ ) and also, no difference was found indicating failure when the mandibular plane angle

Table 3. Days until miniscrew failure, total percentage of failures and average number of days that elapsed before each operator experienced the failures.

\begin{tabular}{|c|c|c|c|}
\hline Failures & Operator 1 & Operator 2 & Operator 3 \\
\hline until day 30 & 4 & 0 & 0 \\
\hline between days 30-60 & 5 & 3 & 1 \\
\hline between days 60-90 & 2 & 4 & 1 \\
\hline between days $90-120$ & 1 & 1 & 2 \\
\hline between days $120-365$ & 3 & 3 & 2 \\
\hline Total until day 120 & $12=80 \%$ & $8=66.67 \%$ & $4=40 \%$ \\
\hline Total after day 120 & $3=20 \%$ & $4=33.33 \%$ & $6=60 \%$ \\
\hline Failure $/$ Total $=\%$ value & $15 / 99=15.15 \%$ & $12 / 96=12.5 \%$ & $10 / 98=10.2 \%$ \\
\hline $\begin{array}{l}\text { Average number of } \\
\text { days until failure }\end{array}$ & $\begin{array}{c}73.87 \\
\text { (SD 69.9) }\end{array}$ & $\begin{array}{c}151.42 \\
\text { (SD 113.91) }\end{array}$ & $\begin{array}{c}218.70 \\
\text { (SD } 114.79)\end{array}$ \\
\hline
\end{tabular}

$(4,9,11,16)$ was used to classify the three facial patterns $(p=0.7522)$, which disagrees with studies that used other references and found differences between patients with different vertical characteristics $(4,9,11,16)$. Corroborating Kim et al. (11), and very close to the significance level, no significant differences were found in the different directions of force application deployed to achieve the desired type of movement $(p=0.0584)$, although other studies have found a higher rate of failure in vertical forces vs. horizontal forces $(4,8)$ and in forces used for tooth uprighting (9). Thus, the facial pattern and direction of force present unclear influence on the failure rate, and more studies with larger sample sizes are needed to address these features.

Nevertheless, when the need arises to insert an OMS, the force vector for the type of anchorage desired limits the placement sites. Therefore, discussions in the literature have hitherto only provided information about the likelihood of a treatment being successful, since the operator can

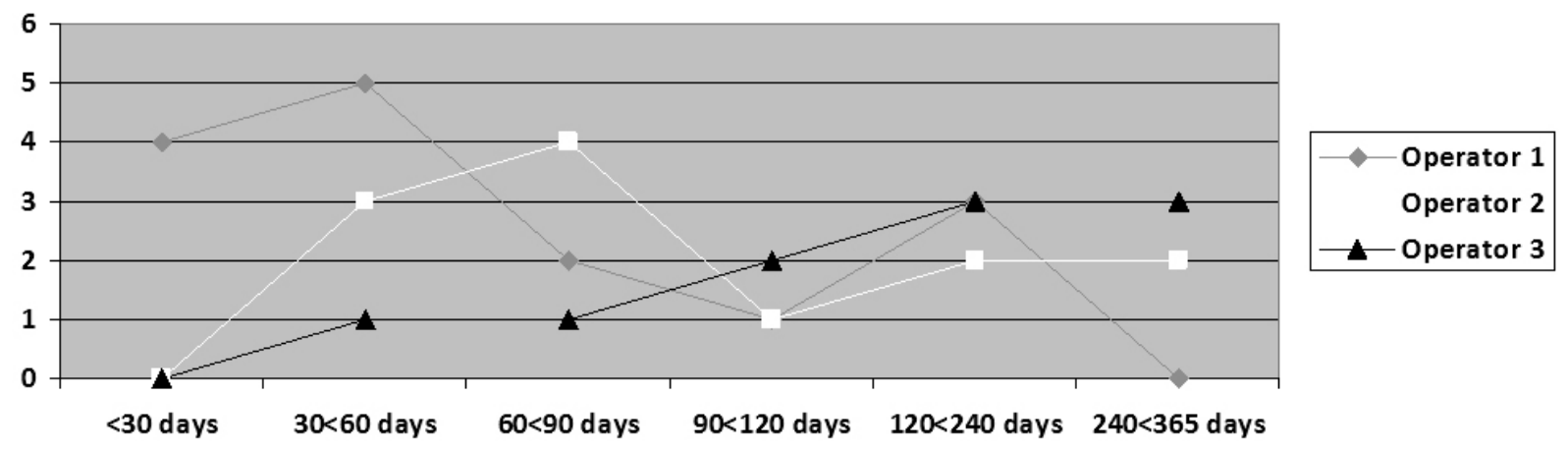

Figure 1. Distribution of miniscrew failures per operator over a 365-day period.

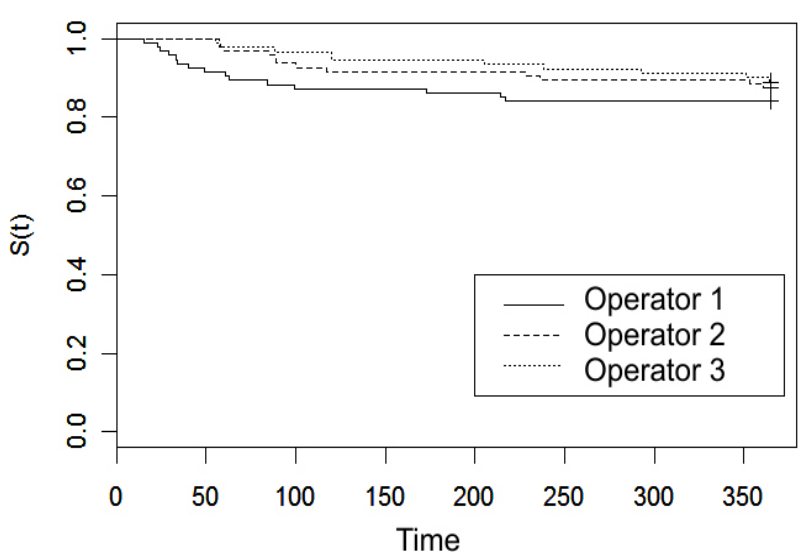

Figure 2. Survival curves of variable "operator". The y-axis shows the proportion of patients with stable OMS at different time points (days on the $\mathrm{x}$-axis).

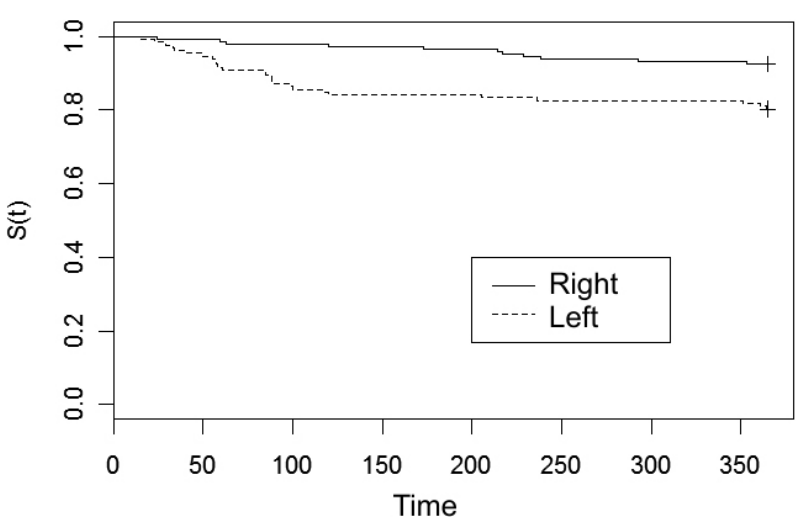

Figure 3. Survival curves of variable "insertion side". The y-axis shows the proportion of patients with stable OMS at different time points (days on the $\mathrm{x}$-axis). The cumulative survival of OMS in the right side was significantly higher than in the left side ( $p=0.0022)$. 
hardly exert any control over factors such as the patient's facial pattern or in which jaw the OMS should be placed. The only single factor that could influence the success rate of OMSs is the operator's experience, related to the surgical technique accuracy, which obviously depends solely on the operator him/herself. This study used 3 instead of several operators with different levels of training and experience since it would pose quite a challenge to place a sufficient number of mini-implants per operator in order to ensure that the analysis would have enough statistical power (0.861). After reviewing the descriptive statistics it was noted that the orthodontist showed the highest failure rate $(15.15 \%)$, followed by the operator with an intermediate level of experience (12.50\%), while the most experienced professional exhibited the lowest failure rate $(10.20 \%)$. However, the test hypothesis showed no statistical significance in terms of success between operators ( $p$-value $=0.8763$ ). The result suggests that regardless of prior operator experience the success rate achieved in placing OMSs 0-100 is nearly identical with that of an experienced operator inserting OMSs 200-300, but it also suggests that may be a higher success rate for the experienced operator if the OMS is required for a short period of time (less than 120 days). Regardless the less experienced operator was not a resident with short clinical experience, this may mean that there is a rapid learning curve for this procedure and that orthodontists, given their knowledge of the force vectors required for treatment even if devoid of experience in dental implantology - can acquire enough knowledge to achieve the same success rate in placing OMSs as an experienced implant dentist. Although some studies show that on models and with prior drilling inexperienced professionals - who are unfamiliar with anatomy - run a greater risk of reaching the roots (10), in a real clinical situation, an increase in the resistance during the placement of the OMS and non-anesthetized periodontal ligament will undoubtedly sound the alarm of a potential risk of root damaging.

The only variable that was significantly associated with "failure" was "insertion side" with a significantly higher failure rate on the left side (18.97\%) compared to the right side $(7.58 \%)(p=0.0022)$. Some researchers found statistical significance and a higher success rate on the left side (5), as the same meaning found to be significant in this study, but on the opposite side (right). This side also exhibited greater failure rates in other studies, with (22) or without $(1,4,15,16)$ statistically significant evidence to account for differences in the success rate. This result may be related to factors such as preferred side of mastication, access difficulties when placing the OMS or viewing the right or left side $(7,10,22)$, different levels of oral hygiene among righties and lefties $(23,24)$, and random statistical errors
(5). Studies differ when trying to show that right-handed (24) or left-handed (25) patients keep better hygiene, or attempting to prove that manual dexterity is not linked to plaque control (23), but motivation is. Park et al. (5) observed that failure is not related to poor hygiene, but rather to local inflammation around the microscrews. This inflammation may be more a result than a cause of failure since it cannot be controlled by improving oral hygiene (11). We agree with Cho et al. (10) that, between the three right-handed operators observed in this study, the habitual posture developed with clinical experience could have a negative impact on success rates, depending on the surgery site, which may affect the view angle and instrument access, although these factor deserves further investigation.

As for failure time, it was observed that OMSs inserted on the left side experience decreased survival odds, especially between 50 and 100 days after placement, similar to what Wiechmann et al. (13) found, i.e., that most of the failures occurred between 100 and 150 days after insertion. Kim et al. (11) found that OMS failures occurred on average after 3.5 months, unlike this study (4.9 months). Besides, even though they started their evaluation with only one inexperienced operator, they argued that operator experience can affect the success rate, which increased from $75 \%$ to over $90 \%$ after insertion of more than 36 OMSs. Moon et al. (16) showed that, after excluding from this failure rate calculation the first 10 OMSs placed by clinicians, almost $80 \%$ of the failures occurred in the first four months, i.e., $32.5 \%$ in the first month. They further concluded that, in general, operator experience did not affect the success rate, although this figure increased after 40 OMSs had been inserted (12). These findings resemble the values found in this study for the first operator, which lost $26.67 \%$ of the OMSs he inserted in the first month, with $80 \%$ of failures concentrated in the first four months. In the first month the other operators showed no failures. Moreover, the failures that took place in the first four months accounted for $66.67 \%$ and $40 \%$ of the total number of failures for operators 2 and 3 respectively. The average number of days before failure occurred for the three operators respectively was 73.87 days, 118.09 days and 218.75 days, with an average of 148 days.

Limitations of this study include a small sample in some areas, low statistical power relative to failure, small number of operators and difficulty in creating a predictive model based on clinical cases. Future studies are warranted to shed further light on these issues by evaluating these deficiencies and determining which factors, individually or in interaction, are relevant to achieve clinical success in the use of microscrews. Until then, the failure risk should be reported to the patient and taken into consideration 
in all treatment plans.

With an overall success rate of $87.37 \%$, the only variable found to be significant was "insertion side", with 3.088 more likelihood of a microscrew failing if placed on the left side than on the right side. The procedure used to place microscrews involved a rapid learning curve by the inexperienced operators, which would justify their placement by an orthodontist.

\section{Resumo}

0 objetivo deste estudo foi examinar se fatores como sitio de inserção, padrão facial do paciente, características do microparafuso, tipo de movimento dental desejado, nivel de experiência com microparafusos e expertise do operador têm associação com o insucesso de microparafusos. Após a aprovação em um comitê de ética, 166 pacientes de uma clínica assinaram um consentimento informado e receberam 293 microparafusos aleatoriamente distribuidos entre 3 operadores com diferentes niveis de experiência prática e expertise no manuseio de microparafusos. Os microparafusos foram observados por um periodo de 365 dias ou pelo tempo necessário de aplicação de forças ortodônticas e as variáveis independentes foram registradas. Análise do teste de qui-quadrado não produziu evidência suficiente para afirmar que existe associação entre a variável "insucesso" e as variáveis "maxila" ( $p=0,4775)$, "face" $(p=0,1081)$, "padrão facial" $(p=0,7522)$, "comprimento do microparafuso" $(p=0,9113)$, "movimento desejado" $(p=0,0584)$, e "operator" ( $p=0,5785)$. A variável "lado de inserção" foi significantemente associada a "insucesso" ( $p=0,0022)$. Em uma análise de sobrevivência de 365 dias, o teste Log Rank resultou em um p-valor de 0,00178 para a curva da variável "lado de inserção" e não mostrou evidência suficiente para as outras variáveis. Com um sucesso total de $87,38 \%$, a única variável significante encontrada foi "lado de inserção" ( $p=0,0022)$, com uma chance 3,088 vezes maior de se perder o microparafuso instalado do lado esquerdo do que do lado direito. 0 procedimento de inserção dos microparafusos envolveu uma rápida curva de aprendizado para um operador inexperiente, o que justifica sua instalação pelos ortodontistas.

\section{References}

1. Papageorgiou SN, Zogakis IP, Papadopoulos M. Failure rates and associated risk factors of orthodontic miniscrew implants: A metaanalysis. Am J Orthod Dentofacial Orthop 2012;142:577-595.

2. Jung RE, Pjetursson BE, Glauser R, Zembic A, Zwahlen M, Lang NP. A systematic review of the 5 -year survival and complication rates of implant-supported single crowns. Clin Oral Imp Res 2008;19:119-130.

3. Miyawaki $\mathrm{S}$, et al. Factors associated with the stability of titanium screws placed in the posterior region for orthodontic anchorage. Am J Orthod Dentofac Orthop 2003;124:373-378.

4. Antoszewska J, Papadopoulos MA, Park, HS, Ludwig B. Five-year experience with orthodontic miniscrew implants: A retrospective investigation of factors influencing success rates. Am J Orthod Dentofacial Orthop 2009;136:158.e1-158.e10.

5. Park HS, Jeong SH, Know OW. Factors affecting the clinical success of screw implants used as orthodontic anchorage. Am J Orthod Dentofacial Orthop 2006;130:18-25.

6. Brettin BT, Grosland NM, Qian F, Southard KA, Stutz TD, Morgan TA, et al.. Bicortical vs monocortical orthodontic skeletal anchorage. Am J Orthod Dentofacial Orthop 2008;134:625-635.

7. Shinohara A, Motoyoshi M, Uchida Y, Shimizu N. Root proximity and inclination of orthodontic mini-implants after placement: cone-beam computed tomography evaluation. Am J Orthod Dentofacial Orthop 2013;144:50-56

8. Kuroda S, Sugawara Y, Deguchi T, Kyung HM, Takano-Yamamoto T. Clinical use of miniscrew implants as orthodontic anchorage: success rates and postoperative discomfort. Am J Orthod Dentofacial Orthop 2007;131: 9-15.

9. Chen YJ, Chang HH, Lin HY, Lai EH, Hung HC, Yao CC. Stability of miniplates and miniscrews used for orthodontic anchorage: experience with 492 temporary anchorage devices. Clin Oral Implants Res 2008;19:1188-1196.

10. Cho UH, Yu W, Kyung HM. Root contact during drilling for microimplant placement. Angle Orthod 2010;81:130-136.

11. Kim, YH, Yang, SM, Kim S, Lee JY, Kim KE, Gianelly AA, et al.. Midpalatal miniscrews for orthodontic anchorage: Factors affecting clinical success. Am J Orthod Dentofacial Orthop 2010;137:66-72.

12. Lim HJ, Eun $\mathrm{CS}$, Cho JH, Lee, $\mathrm{KH}, \mathrm{H}$ wange HS. Factors associated with initial stability of miniscrews for orthodontic treatment. Am J Orthod Dentofacial Orthop 2009;136:236-242.

13. Wiechman D, Meyer U, Büchter A. Success rate of mini- and microimplants used for orthodontic anchorage: a prospective clinical study. Clin Oral Implants Res 2007;18:263-267.

14. Chen Y, Kyung HM, Zhao WT, Yu WJ. Critical factors for the success of orthodontic mini-implants: A systematic review. Am J Orthod Dentofacial Orthop 2009;135:284-291.

15. Min KI, Kim SC, Kang KH, Cho JH, Lee EH, Chang NY et al. Root proximity and cortical bone thickness effects on the success rate of orthodontic micro-implants using cone beam computed tomography. Angle Orthod 2012:82:1014-1021.

16. Moon CH, Park HK, Nam JS, Im JS, Baek SH. Relationship between vertical skeletal pattern and success rate of orthodontic mini-implants. Am J Orthod Dentofac Orthop 2010;138:51-57.

17. Viwattanatipa N, Thanakitcharu S, Uttraravichien A, Waranuch P. Survival analyses of surgical miniscrews as orthodontic anchorage. Am J Orthod Dentofacial Orthop 2009;136:29-36.

18. Kim YK. Effects of the taper shape, dual-thread, and length on the mechanical properties of mini-implants. Angle Orthod 2009;79:908914.

19. Baumgaertel S. Predrilling of the implant site: Is it necessary for orthodontic mini-implants? Am J Orthod Dentofacial Orthop 2010;137:825-829.

20. Holm L, Cunningham SJ, Petrie A, Cousley RRJ. An in vitro study of factors affecting the primary stability of orthodontic mini-implants. Angle Orthod 2012;82:1022-1028.

21. Laursen MG, Melsen $B$, Cattaneo PM. An evaluation of insertion sites for mini-implants: A micro-CT study of human autopsy material. Angle Orthod 2013;83:222-229.

22. Karagkiolidou A, Ludwig B, Pazera P, Gkantidis N, Pandis N, Katsaros C. Survival of palatal miniscrews used for orthodontic appliance anchorage: A retrospective cohort study. Am J Orthod Dentofacial Orthop 2013;143:767-772.

23. Bercy $\mathrm{P}$, Tenenbaum $\mathrm{H}$. Manual dexterity and acquisition of correct dental hygiene. Rev Belge Med Dent (1984) 1989;44:110-114.

24. Çakur B, Yildiz M, Dane S, Zorba YO. The effect of right or left handedness on caries experience and oral hygiene. J Neurosci Rural Pract 2011;2:40-42.

25. Tezel A, Orbak R, Canakci V. The effect of right or left handedness on oral hygiene. Int J Neurosci 2001;109:1-9

Received June 14, 2014 Accepted August 22, 2014 